\title{
CASES OF OPHTHALMOLOGICAL AND NEUROLOGICAL INTEREST
}

BY

\author{
JAMES TAYLOR
}

LONDON

Ir has long been recognized that ophthalmology and neurology touch each other at many points. I think the following cases illustrate this intimate relationship in a somewhat striking manner and that for this reason they are worthy of record.

The first case is that of a member of our own profession, aged j0 years, whom I saw in February, 1919, with Dr. Randall, of Wimbledon. When I saw him he was apparently quite unconscious although he told me afterwards that he had a vague recollection of seeing me. His eyes were partially open, there was well-marked ptosis on the left side, and there was squinting with external deviation of the left eye. His optic discs were normal and all his reflexes were normal.

I got from him some months later his history. On Christmas night of 1918 he had a violent attack of diarrhoea and vomiting. He had not felt well all day and had eaten sparingly so that the attack was not the result of any dietetic error or excess. After this he experienced vague pains and a sensation as if his head were being drawn downwards and forwards. There was double vision for two or three weeks before he eventually had to take to bed, and he also experienced vague blue mists at this time. He engaged a locum tenens, and the next day he became unconscious and remained for some time in the condition in which he was when I saw him. We concluded that it was a case of encephalitis lethargica and the subsequent course proved this to be correct. He recovered and was able to resume his practice but when I saw him a few months later he exhibited a marked condition of the Parkinsonian sequel to encephalitis lethargica. His ocular movements were good except that upward movements of both eyes were restricted.

The next case is that of a man, aged 58 years, whom I saw with Dr. Swayne on April 11, 1924. The only matter of significance in his previous health was that in 1893 he had had an attack of enteric in which he was said to have nearly died. Three or four weeks before I saw him he had had a febrile attack with sleeplessness, restlessness, and delirium. He had a sore throat and found one morning that he had diplopia. This lasted for eight or ten days and then passed off. He had one attack of sickness. I)r. Swayne did not see him until the feverish attack had passed off. When I saw him he felt weak and could not walk more than half 
a mile. His taste and smell were defective and he was always sleepy. There was no headache, his reflexes were normal, and his ocular movements were good with punctuation on external deviation. There was no diplopia. I saw him on two occasions later, on May 24 and September 24. He had been away and had been resting, was better while away but the tiredness returned when he resumed work. He was seen by an ophthalmic surgeon who suggested intracranial growth but he never had anything to indicate definitely such a condition. He gradually became weaker, developed signs of bulbar involvement and died about eight months after I first saw him. I think this also was a case of encephalitis lethargica.

The next case is that of a lady, aged 46 years, whose history was difficult to obtain. I saw her in April, 1920, on account of headache and giddiness. Two and a half years before this she had had "dazzlings"--apparently ocular sensations associated with giddiness. In 1919 she had some teeth out and had five injections of some vaccine. She felt very ill after them and had a fit in May, 1919, in which she dislocated her shoulder-not an unusual effect of an epileptic fit. She also had an attack of shingles, and I may mention, incidentally, that within a week or two her daughter had chicken-pox. When I saw her she had double papilloedema, some headache and a history of recent vomiting. I was told that her blood and cerebro-spinal fluid had been examined, but I could not find out if a Wassermann had been done. A skiagram of her skull was negative. She was seen by another neurologist who strongly urged decompression, a procedure to which I demurred, and it was finally arranged that an ophthalmic surgeon should see her and carefully observe the amount of swelling, and only if sight were definitely threatened recourse was to be had to decompression. She was seen and watched by $\mathrm{Mr}$. Fisher, and the papilloedema gradually subsided. I saw her on October 6, 1924, and her vision was good, the discs although a little pale showed no swelling and her general health was excellent.

The next case is that of a young clergyman who was sent to me by Mr. Inman of Southsea on September 25, 1922. Three weeks previously he noticed that his sight was not quite. as usual. A week later he saw Mr. Inman who found a central scotoma in each eye and impaired vision. His sinuses were examined and found normal, his Wassermann was negative, and his urine normal. A few days later a small haemorrhage was noticed at the edge of the right disc and slight papilloedema was present in each eye. He became rapidly worse. There was marked papilloedema when I saw him, with swelling of about 3D., and no perception of light. X-ray examination of the skull revealed 
nothing abnormal and the opinion was expressed that it was a case of so-called retrobulbar neuritis and the hope was expressed that it might clear up. Within twenty-four hours he was able to recognize the presence of a candle. Mr. Collins saw him and agreed with the diagnosis. He was put on iodide, but it is significant perhaps that improvement had set in before he had taken the iodide. He made a complete recovery and when I saw him three years later, he looked in excellent health, had had no trouble with his eyes, his vision was good, although his optic discs were pale. I have recently (February 23, 1928) had a report from him that he has remained quite well.

The next case is one which I venture to think contains lessons for ophthalmic surgeons as well as neurologists. In April, 1921, a boy, aged $11 \frac{1}{2}$ years, was brought to me by Dr. Gibson, with the history that he had suffered from headaches in the previous term at a preparatory school at Eastbourne. He was not a particularly clever boy, but he was sturdy and strong looking, and was not inclined to make too much of his headaches. He had not had any sickness. The day before I saw him he had seen an eminent ophthalmic surgeon who after examining his eyes had sent him on to an equally eminent neurologist-who, it seems to me on quite insufficient evidence, had boldly diagnosed intracranial growth and told an anxious mother that her boy was suffering from "the most incurable of all diseases-a growth in the brain." On examining the boy I found he had very red discs-and in the absence of any other signs of intracranial trouble, I formed the opinion that the condition was a physiological one-a so-called hypermetropic disc, although there was no hypermetropia.

A month later I wished his mother to take him to see the ophthalmic surgeon who had seen him before, but she declined to do this, and $\mathrm{Mr}$. Treacher Collins saw him and agreed that the condition was not pathological. I may mention that the boy has remained well ever since and has pursued his career at a public school.

I have had a letter this month (Feb. 1928) from his doctor to say that he has recently seen him on account of a slight football accident and he has remained perfectly well in the meantime. 